\title{
Experience from In-depth Analysis of Road Accidents
}

\author{
J. Andres*, S. Kratochvílová, J. Křenek, J. Rücker, K. Poláčková, B. Turošíková, J. Frič \\ CDV-transport Research Centre, Brno, Czech Republic \\ *Corresponding author: josef.andres@cdv.cz
}

L. Plánka, M. Krtička

The University Hospital Brno, Brno, Czech Republic

DOI: $10.2478 / \mathrm{v} 10158-012-0019-y$

\begin{abstract}
Official road accident statistics are, in most countries, not sufficiently detailed to allow an in-depth analysis of accidents. In-depth studies try to provide a detailed reconstruction of events that lead to accidents and to identify the factors that caused injuries. According to Elvik (2010), the purpose of performing in-depth analyses of accidents is both to understand factors leading to accidents and to identify the best way to prevent accidents. In-depth studies of fatal accidents have a long history in Finland (VALT, 2004) and the United Kingdom (Staughton \& Storie, 2000), but have more recently been introduced in Sweden (Sagberg \& Assum, 2000) and Norway (Assum \& Sørensen, 2010). In recent years, in-depth studies in Finland have focused on factors that influence the injury severity (Toivonen, 2006). Germany (Otte, 1994) and the Netherlands (Vollenhoven, 2001) also perform in-depth studies of accidents, as well as Denmark (Larsen, 2004).
\end{abstract}

KEY WORDS: In-depth analysis of road accidents, transport infrastructure, vehicle engineering, psychological experts in transport, road accident, traffic area, vehicle, accident with injuries.

\section{INTRODUCTION}

In 2011, the Czech Transport Research Centre (Centrum dopravního výzkumu, v.v.i.) started an R\&D project of the Ministry of Interior entitled In-depth Analysis of Road Accidents (Hloubková analýza silničních dopravních nehod), project No. VG20112015007 (hereinafter referred to as HADN). A specialized team of experts in transport infrastructure, vehicle engineering, psychology in transport, and cooperating medical experts from The University Hospital Brno investigate accidents on the spot occurring in Brno and its surrounding, and later analyse them and record them in a database specifically created for this purpose (Andres, 2009). A similar project GIDAS, which has been running in Germany for several decades, is a model and guideline for this work. The project aims to create a database of detailed information on road accidents which can be used for making important transport and political decisions and to operatively design road safety measures in the above mentioned areas. Within the duration of the project HADN, i.e. in 2011 and 2012, more than 300 accidents, which included injuries and, in some cases, fatal injuries, were investigated. By the end of the project, i.e. by 2015 , it will have been necessary to have analyzed nearly 750 road accidents. Although the existing "sample" of accidents is still statistically insignificant, some of the findings and relationships which are the topic of this 
article are already obvious (Andres, 2011). Therefore, the in-depth analysis of road accidents can lead to the application of effective road safety measures, as well as to the reduction of the number and severity of road accidents.

\section{DESCRIPTION OF ACTIVITY}

\subsection{Transport infrastructure}

Road safety also depends on the safety of road infrastructure. Although the majority of accidents are caused by drivers, their behaviour is often influenced by the traffic environment. While various sources indicate that in up to $25 \%$ of cases the transport environment influences the occurrence of road traffic accidents, HADN investigations of accidents found that the transport infrastructure more or less affected almost $42 \%$ of all investigated traffic accidents! And it may not only concern the typical limited visibility or fixed obstacles to traffic, but also the problem of a poor road surface (motorway D1 is an example) or its inappropriate gradient. Based on the dealings with accidents, recommendations concerning road safety were designed that should eliminate the possibility of further accidents. Although from the viewpoint of statistical significance, the number of accidents is still insufficient, several measures were generalized and their incorporation could begin to start to lead to the relevant technical regulations. The following graph shows the designed measures (recommendations) to improve safety in traffic area.

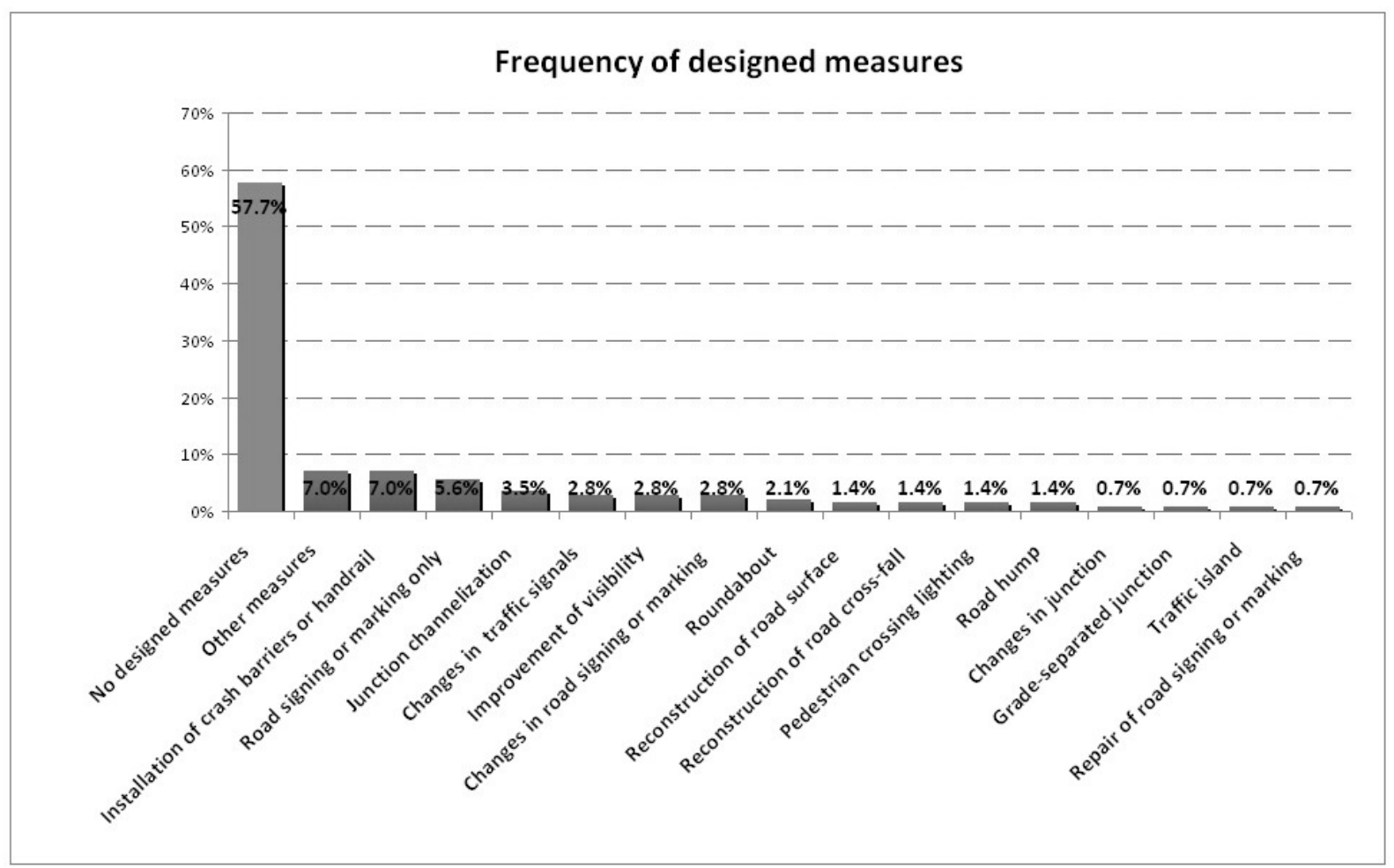

Figure 1: The proportion of road safety measures in the area of transport infrastructure.

Regarding the graph above it should be mentioned that the first column "No designed measures" does not mean that the researchers analyzing accidents did not deal with the influence of the traffic area on the accidents, but rather that within an in-depth analysis of the accident spot, no deficiency was found that could have had an effect on the occurrence of traffic accidents and their consequences. 


\subsection{Vehicle engineering}

As part of a comprehensive investigation of all the circumstances under which the accident occurred, it is also important to examine in detail the technical condition of the vehicle. The purpose of the work of vehicle engineers is to confirm or disprove that the main causes of accident were technical faults in the vehicle. By October 2012, a total of 412 vehicles were involved in 257 investigated traffic accidents. All types of motor vehicles and bicycles were involved. A detailed analysis of traffic accidents in terms of vehicle engineering revealed that a defect in the vehicle, as the only cause of an accident, was detected in only one case. So in terms of vehicle engineering, we can only talk about implications and not the causes of traffic accidents resulting from a technical fault in the vehicle. The most common factor of traffic accidents included particularly neglecting the condition and pressure of tyres, lack of inspection of the vehicle before driving, failure to ensure sufficient field of vision from the vehicle under difficult weather conditions, unused passive safety features provided as part of the vehicle equipment, and underestimation of necessary driving skills, or their lack.

During the research it was found that most accidents occurred due to the insufficient ability to stop a vehicle, followed by a collision with a vehicle driving in front. The number of vehicles involved in a collision were two (in 94 accidents), three (in 18 accidents) and in four cases even four vehicles travelling closely one behind another. The most frequent cause of accidents was a failure to keep a safe distance and adjust the speed to the situation on the road. The second largest group was represented by an accident between a pedestrian and a vehicle (51 accidents). These accidents occurred mainly because of a sudden move of the pedestrian into the path of the vehicle, and due to overlooking the pedestrian by the driver (collision with a pedestrian at low visibility, dark colour clothing of a pedestrian, etc.). It was found that vehicle drivers were liable for the accident in 22 cases. The Figure 2 shows a relatively high occurrence of accidents where a motorcycle was involved and accidents of a motorcycle and one car. In each of these groups, 40 accidents were investigated. Accidents of motorcycles and those involving motorcycles occurred mainly due to loss of control of the motorcycle when taking a curve at high speed, or the falling of a motorcycle when braking. In 13 cases, one-vehicle accidents involved the vehicle overturning. An important group of traffic accidents is represented by the accidents of cyclists (alone in 9 cases) and accidents involving cyclists (19 accidents). Similar to accidents with motorcyclists it showed that the main causes involved the loss of control of a bike on uneven surfaces and overlooking a ridden bicycle by a vehicle driver. Other significantly represented groups of traffic accidents are those that involve a collision of a vehicle with a fixed obstacle, and accidents involving public transport vehicles.

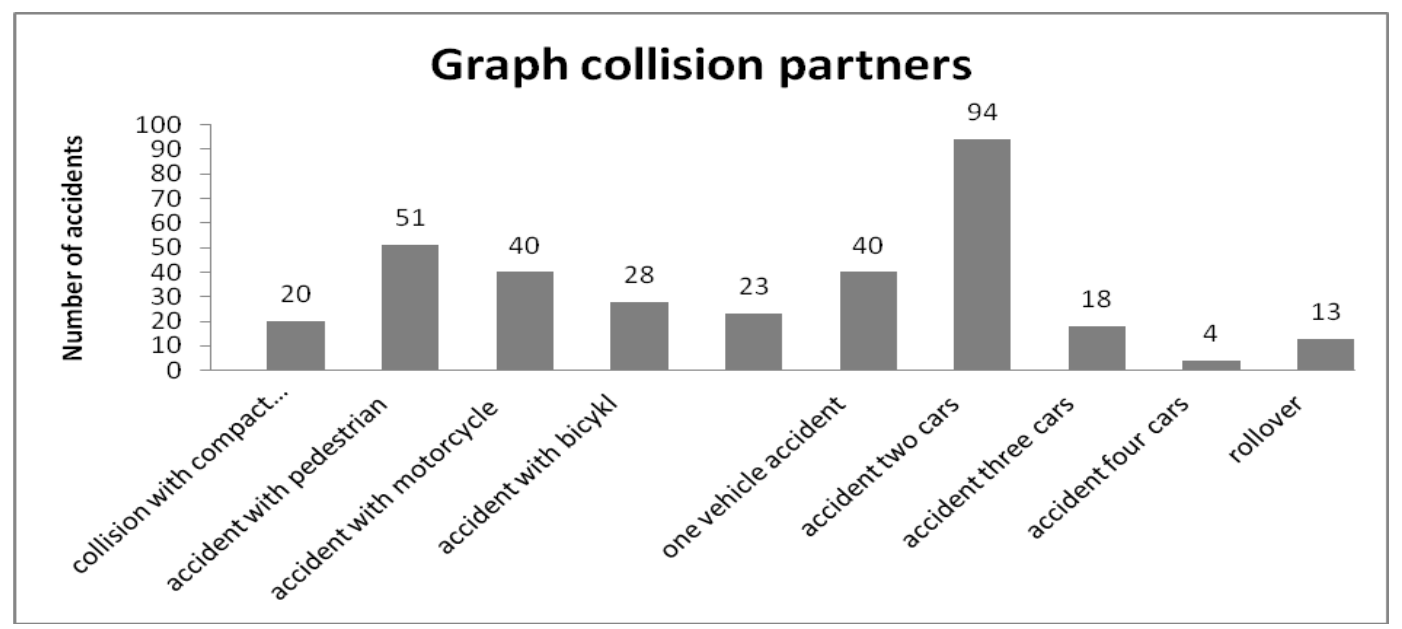

Figure 2: Distribution of the number of traffic accidents, depending on the type of a collision partner. 
As regards the vehicles involved in the accidents investigated, it can generally be said that the condition and age of the tyres have a significant influence on the course and consequences of traffic accidents. Current findings suggest that drivers use tyres of the prescribed size although often of earlier production date, insufficient tread depth or underinflated. As regards tyre age, most often represented were 3 years old tyres, followed by the group of 4 and 5 years old tyres. As a matter of interest, even 18 to 24 year-old tyres were reported. During the period specified for the use of winter tyres (from 1 November to $31 \mathrm{March}$ ) it was found that this requirement was not met in only 6 out of 135 examined vehicles in the specified period.

As concerns the above mentioned issue of overlooking another road user it was found that the omission was due to their "hiding" behind the right front pillar or their location in a driver's blind spot.

A serious traffic accident also occurred because of the incorrect placement and securing of goods. In one case the transported goods intruded into the vehicle crew's compartment. In another accident (head-on collision) there was an explosion of a gasoline canister located in the storage compartment in the front part of the vehicle.

Last, but not least, when investigating accidents it was found that in many cases vehicle headlights were not turned on, a clear view from the vehicle in poor weather and light conditions was not secured, safety belts were not used (or were used improperly) or the technical check of the vehicle was not valid. In these cases it is only possible to appeal to drivers to adequately check the vehicle prior to driving. In 2012 it was registered at sites of accidents whether participants of accidents used reflective vests on accident sites. It was found that out of 322 traffic accident participants, only 70 of them put on their vests after an accident, which represents only $22 \%$ of the people involved. This number included only persons at the spot of an accident who were neither members of the rescue teams nor the research team. Among the participants, employees of towing services, undertakers' employees and employees of assistance services were also included. The data are shown in Figure 3.

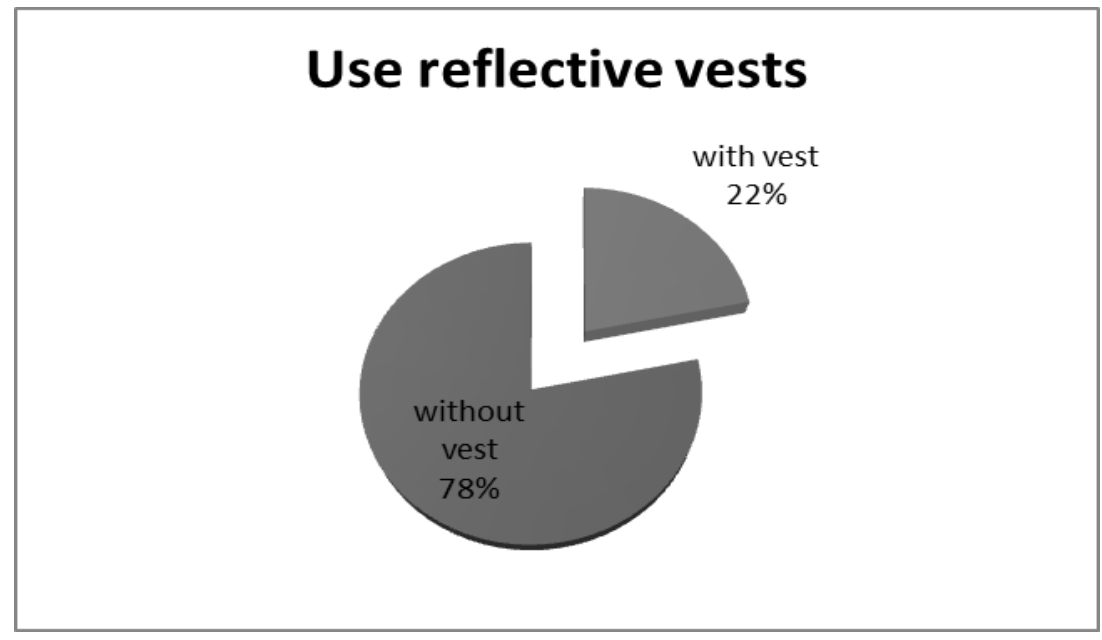

Figure 3: Dividing traffic accident participants present on the spot according to the use of reflective vests.

Figure 4 shows the age of the vehicles investigated within the analysis of traffic accidents. The largest group is represented by 11 years old vehicles, followed by vehicles of 6 and 10 years of age. Fifteen vehicles were older than 25 years. These were mainly public transport vehicles - trams. 


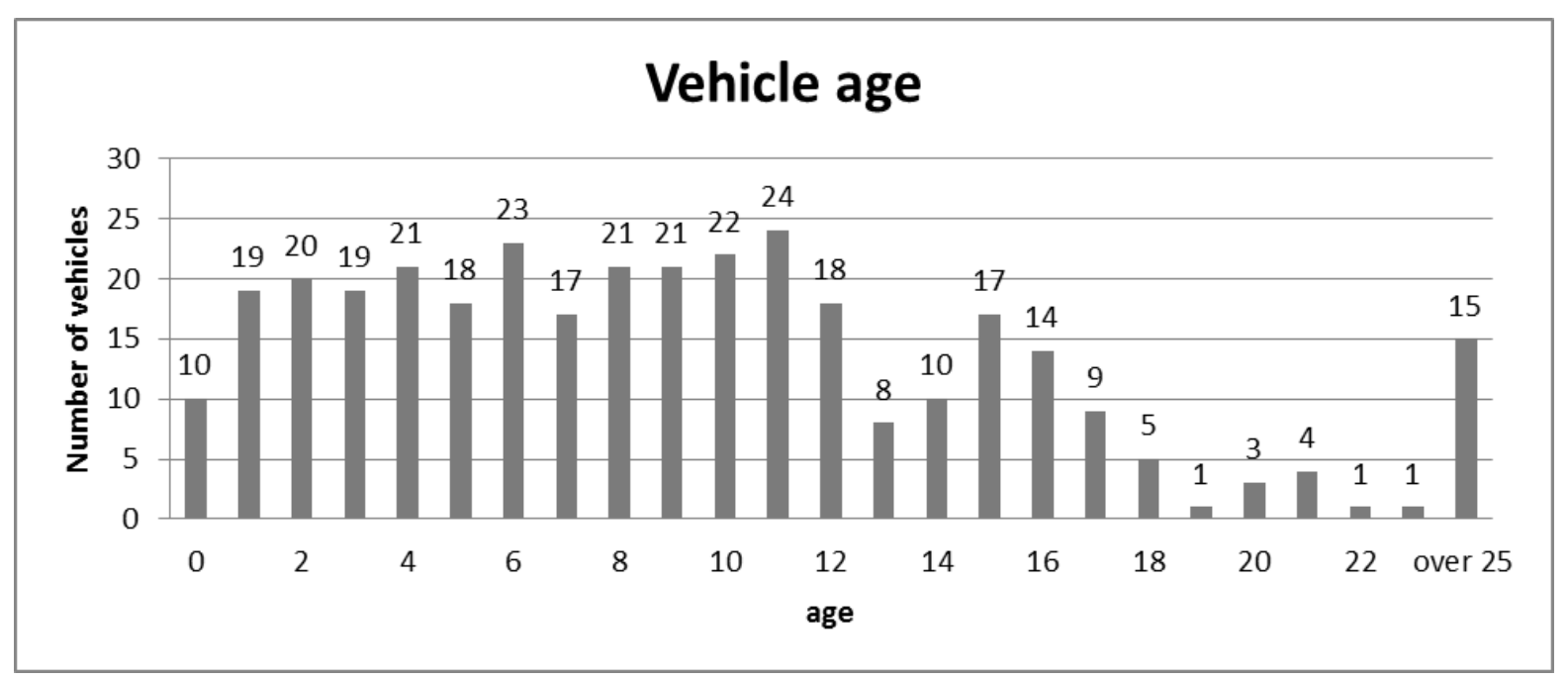

Figure 4: The age of vehicles investigated through an in-depth analysis of traffic accidents.

\subsection{Psychological aspects of transport}

From the perspective of the human factor the following findings have been achieved than can be seen from Figure 5. Due to the low number of data obtained so far they must be seen as descriptive statistical data. Inattention has so far been found to be the most significant psychological phenomena involved in the occurrence of traffic accidents - in almost half of all cases. The decline in attention was mainly caused by the other activities of the participants of accidents (smoking, eating, handling a mobile phone or other objects, interaction with passengers). The attention of participants was increasingly exerted especially in unclear traffic situations, in case of changes on accident spots or when driving a vehicle in an unfamiliar place. In 26 cases attention decreased during routine rides. In 22 cases, accidents took place with the active participation of persons younger than 25 years or older than 65 years. Persons in the period of young adulthood are less experienced in driving. It can be expected that people over 65 years show a decline in cognitive functions, which is associated with prolongation of reaction time, constriction of visual field and slowing of thought processes (Havlík, 2005). These specificities could occur also in people surveyed in the project HADN. Driving under the influence of intoxicating and addictive substances, mainly alcohol, was reported in 21 cases. Fatigue and sleep were detected in 12 cases, particularly at night and early morning hours, with the common denominator of the absence of passengers or vehicle crew. The average sleep time of these drivers before the accident was 6 hours. In 7 cases, the culprits of accidents reported their negative emotional mood state caused by a disturbance before the drive or during it. Six people were experiencing health problems that had direct influence on the accident. In addition to chronic and acute diseases, suicide was accomplished in one case. As concerns the specific group of road accidents represented by accidents with pedestrians, we have dealt with fifty-one cases. In addition to inattention on both sides, i.e. vehicles and pedestrians, this type of accident is influenced, especially under low visibility conditions, by dark coloured clothes and the absence of reflective elements. 


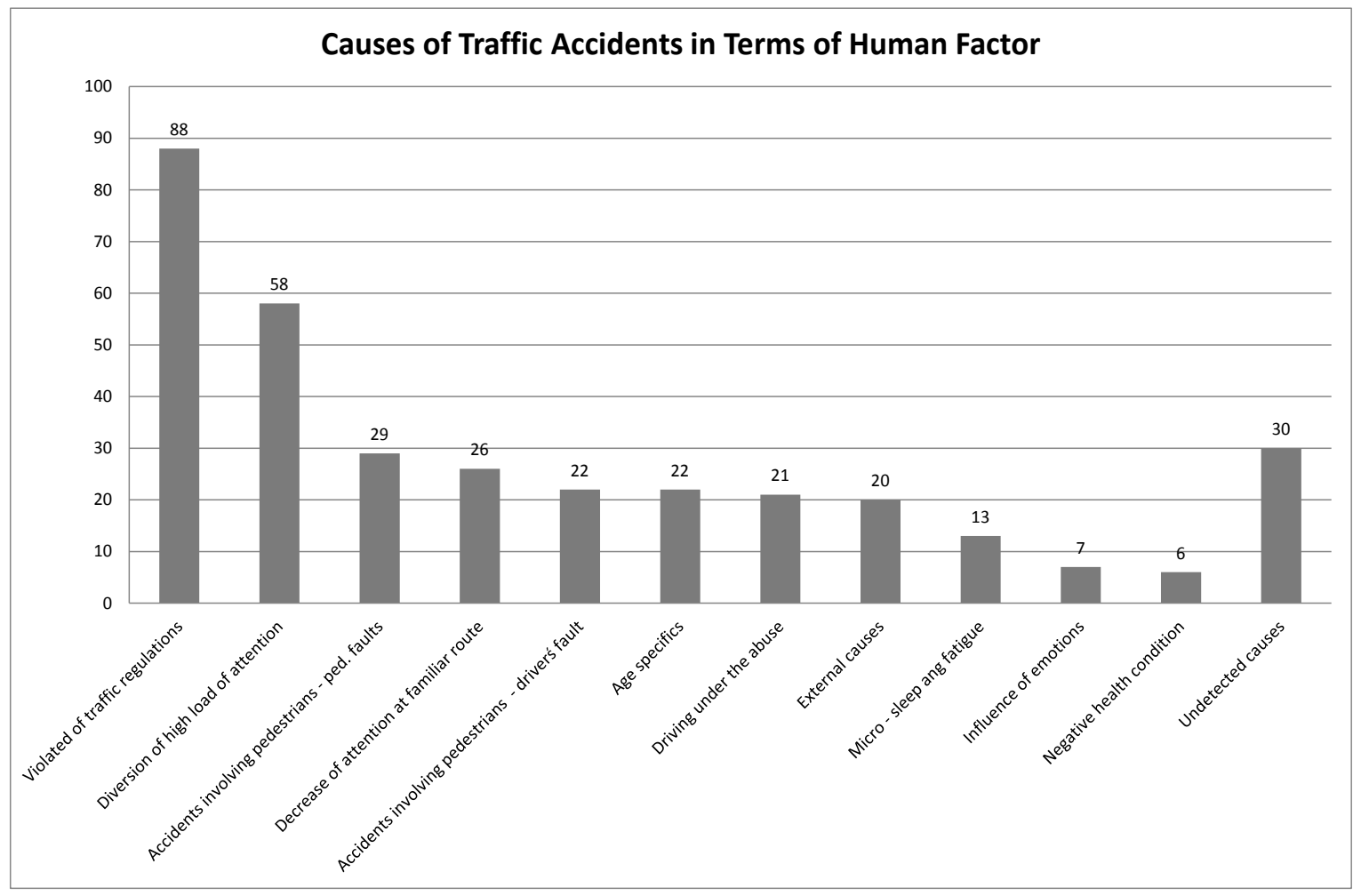

Figure 5: Causes of accidents from the perspective of the human factor.

\subsection{Health consequences of traffic accidents}

Among the injured in traffic accidents in the years 2011 and 2012, males dominated. The average age of patients at the time of hospitalization was 47 years. As in recent years, and also in the examined period, traffic accidents were a major cause of serious injuries, representing almost a half of all injuries. ISS (Injury Severity Score) is used for the evaluation of the severity of injuries, and its average distribution during the monitored period was as follows: among the injured, $83.1 \%$ of them attained ISS $16-30,10.5 \%$ ISS $31-45$ and $6.5 \%$ ISS $\geq 45$. The average time patients spent in the emergency department with their primary examination and treatment was 105 minutes. Among the diagnoses of the patients, cranial traumas, injuries to the limbs and chest and spleen, and spinal injuries dominated. The average length of stay of patients was 18 days. Lethality of seriously injured patients in the year 2011 was $9.3 \%$.

We have also examined the position of the injured persons in the vehicle or outside the vehicle at the time of the accident. Their number was determined according to the frequency of use of the vehicle and the total number of accidents. Most people were injured in cars, namely $53.2 \%$ of all injured persons. The injured drivers both of double-track vehicles and single-track vehicles formed the largest group. The results are shown in the following graph. 


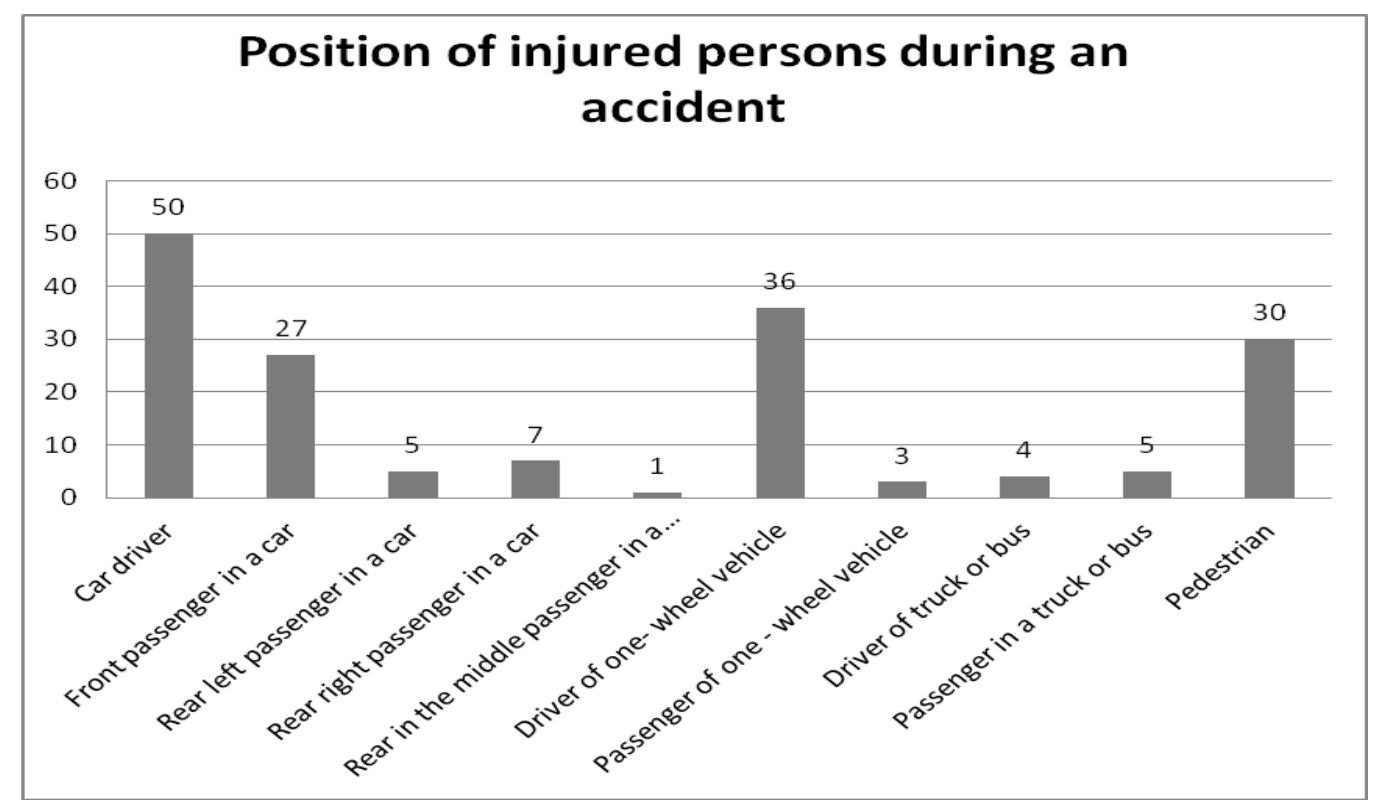

Figure 6: Position of injured participants of accidents.

\section{CONCLUSION}

The purpose of this article is to familiarize the professional community with the first experience obtained through an in-depth analysis of road traffic accidents, which represents one of the possibilities of a proactive approach to the solution of issues connected with traffic accidents. The analysis should be completely independent of the activities and achievements of organizations and institutions that are legally required to take part in solving and liquidation of traffic accidents (first aid services, investigating authorities of the Police of the $\mathrm{CR}$, fire fighters). The aim of this in-depth analysis of traffic accidents is to obtain reliable and undistorted knowledge about the origin, cause and consequences of traffic accidents, with a special emphasis on finding the root causes and their formation (Andres, 2009; VALT, 2004).

The analysis was carried out comprehensively and with a consideration of transport infrastructure, vehicles involved and participants of accidents.

Although the duration of the project is proposed for 5 years, it is even now possible to trace some dependencies that affect both the emergence and cause of traffic accidents. The results of the current accident survey not only confirmed some "well-known findings" such as the fact that the non-use of helmets by cyclists is a risk, which reflects in a significant deterioration of the consequences of accidents, but it also detected many other factors connected with accidents, including the following points: Inadequate storage of luggage and, on numerous occasions, of dangerous loads in passenger cars, the lack of elimination of blind spots, particularly in older trucks and buses, and actual details about the (non-)activation of airbags in accidents, are also of interest.

It is also well known that the quality of road surfaces in our country is rather low. This fact is also reflected in accidents, where the unevenness of the road surface could lead to the loss of control of a vehicle and consequently to a skid. Road places with improper cross slopes, which contribute to a loss of vehicle stability were also detected (Andres, 2011).

Based on the investigated accidents, we can already see areas for recommending changes in legal and technical regulations in the transport infrastructure, as well as in vehicle engineering and the education of drivers. They are, however, not sufficiently supported so far by statistically significant results of the investigation of accidents and cannot therefore be administered yet, after less than 2 years of accident research. 
In the area of transport infrastructure we can speak about confirmation of knowledge that is wellknown among professionals, of what a safe traffic area should look like. Deficiencies lie rather in the implementation of that knowledge and assuring compliance with safety policies.

In the area of vehicle engineering, some suggestions can be made of making amendments to regulations on tyres, the elimination of blind spots in vehicles, airbags, etc. (Andres, 2011).

In the area of preparation of drivers for real traffic it seems that driving skills, especially of young motorcyclists, are insufficient, which deserves addressing. There are also deficiencies in the assessment of not only drivers' health, but also their psychological condition.

\section{REFERENCES}

Andres, J., 2009. Hloubková analýza dopravních nehod - metodika. Brno: Centrum dopravního výzkumu, v.v.i. (in Czech)

Andres, J., 2011. Hloubková analýza dopravních nehod po roční bilanci. Silniční obzor, 72 (11), pp. 320-322. ISSN 0322-7154. (in Czech)

Assum, T., Sørensen, M.V. J., 2010. In-depth study of 130 fatal accidents involving heavy goods vehicles in Norway 2005-2008. Report 1061. Oslo: Institute of Transport Economics.

Elvik, R., 2010. Assessment and applicability of road safety management evaluation tools: Current practice and state-of-the-art in Europe. Report 1113. Oslo: Institute of Transport Economics.

Havlík, K., 2005. Psychologie pro řidiče. Praha: Portál. ISBN 80-7178-542-3. (in Czech)

Larsen, L., 2004. Methods of multidisciplinary in-depth analyses of road traffic accidents. Journal of Hazardous Materials, 111 (1-3), pp. 115-122.

Otte, D., 1994. The accident research unit Hannover as example for importance and benefit of existing in-depth investigations. SAE Technical Paper series No. 940712.

Sagberg, F., Assum, T., 2000. In-depth road accident investigations: aggregated results from 196 fatal accidents in Mälardalen, Sweden, 1997-99. Report 499. Oslo: Institute of Transport Economics.

Staughton, G. C., Storie, V. J., 2000. Methodology of an in-depth accident investigation survey. Report LR762. Crowthorne: Transport Research Laboratory.

Toivonen, S., 2006. Crash violence within the traffic system: risks and their reduction in road traffic on two-lane main roads in Finland. Helsinki: Finnish Road Administration.

VALT, 2004. VALT 2003 method. Helsinki: Finnish Motor Insurers' Centre (VALT).

Vollenhoven, P., 2001. Independent accident investigation: every citizen's right, society's duty. 3rd European Road Safety Lecture. Brussels: European Transport Safety Council.

\section{The article was produced under the support of the project Transport R\&D Centre (CZ.1.05/2.1.00/03.0064)}

